\title{
Minimum Wage, Public Investment, Economic Growth
}

\author{
Minoru Watanabe \\ Graduate School of Economics, Kobe University, Kobe, Japan \\ Email: mino.watanabe@gmail.com
}

Received August 8, 2013; revised September 7, 2013; accepted September 15, 2013

Copyright (c) 2013 Minoru Watanabe. This is an open access article distributed under the Creative Commons Attribution License, which permits unrestricted use, distribution, and reproduction in any medium, provided the original work is properly cited.

\begin{abstract}
This paper considers the relationship between economic growth and minimum wage. Minimum wage helps reduce poverty and maintain a minimum standard of living. However, it is also claimed that minimum wage has a negative effect on employment and GDP. This paper develops a simple two-period overlapping generation model with three economic policies, minimum wage, unemployment benefit, and public investment that improves labor productivity. The government imposes tax on firms to finance public capital and unemployment benefit under a balanced budget. We show that economic growth is promoted with an increase in minimum wage and the ratio of public investment to tax revenue.
\end{abstract}

Keywords: Minimum Wage; Public Investment; Economic Growth

\section{Introduction}

Minimum wage is an economic policy that helps reduce poverty and maintain a minimum standard of living. However, it is also claimed that minimum wage has a negative effect on employment and GDP. Therefore, earlier studies consider the relationship between minimum wage and economic growth in a dynamic framework. Cahuc and Michel [1] introduce human capital accumulation in an endogenous growth model. Ravn and Sorensen [2] consider skill formation accumulated by schooling and training. Askenazy [3] develops endogenous growth model with an open economy and R\&D sector. Irmen and Wigger [4] consider minimum wage with a two-country endogenous growth model. Tamai [5] discusses the interaction between inequality and economic growth from the view point of political economy. The above papers assume two sectors or heterogeneous agents. Fanti and Gori [6] consider the relationship between economic growth and minimum wage under a simple one-sector overlapping generation model with ${ }^{1}$ homogeneous agents. It is ${ }^{2}$ uncertain whether minimum wage promotes economic growth in earlier papers.

This paper introduces public investment that improves labor productivity, for example, infrastructure and medical service. Public investment is an economic policy with

\footnotetext{
${ }^{1}$ They introduce heterogeneous agents in extension.

${ }^{2}$ Whether minimum wage promotes economic growth or not depends on parameters or assumptions in Cahuc and Michel [1], Ravn and Sorensen [2], Askenazy [3], Irmen and Wigger [4], and Fanti and Gori [6].
}

an important role in macroeconomic performance. Barro [7], Futagami, Morita and Shibata [8] examine economic growth with public investment that improves labor productivity. Glomm and Ravicumar [9] discuss economic growth including public investment and human capital accumulation. Yakita [10] considers public investment in an aging society.

Following Fanti and Gori [6], this paper introduces public investment that enhances labor productivity and considers the relationship between minimum wage and economic growth. The results obtained in this study are presented below. First, an increase in minimum wage always promotes economic growth. Second, an increase in the ratio of public investment to tax revenue promotes economic growth.

The remainder of this paper is organized as follows. Section 2 presents our model. Section 3 describes the equilibrium. Section 4 summarizes the paper.

\section{Model}

\subsection{Basic Structure}

The economy in this paper is based on a basic two-period overlapping generations framework. There exist three agents, households, firms, and the government.

\subsection{Households}

Households live two periods, young and old and supply one unit of labor to the labor market. If they are employed they receive wages, and if they are not employed, 
they receive unemployment benefit. The utility function in this paper is:

$$
u_{t}^{i}=\log c_{y, t}^{i}+\beta \log c_{o, t+1}^{i}
$$

where $c_{y, t}^{i}$ is the young-period consumption of household $i, c_{o, t+1}^{i}$ is the old-period consumption of household $i$; $i$ is the index of both employment $(i=e)$ and unemployment $(i=u)$, and $\beta \in(0,1)$ is the constant discount factor. The budget constraint of households $i$ is given as:

$$
\begin{aligned}
& c_{y, t}^{i}+s_{t}^{i}=x_{t}^{i} \\
& c_{o, t+1}^{i}=\left(1+r_{t+1}\right) x_{t}^{i}
\end{aligned}
$$

where $x_{t}^{i}$ is the income in young period, $s_{t}^{i}$ is the savings, and $r_{t+1}$ is the interest rate. If the households are employed, they receive wags, and if they are not employed, they receive unemployment benefit. In this economy, minimum wages exist. Therefore the relation between minimum wage, $w_{m, t}$ and competitive wage, $w_{c, t}$, is given as:

$$
w_{m, t}=\mu w_{c, t}
$$

where $\mu>1$ is the constant mark-up rate that generates unemployment in the labor market. Households receive unemployment benefit $b_{t}$ when they are not employed, and $b_{t}$ is defined as:

$$
b_{t}=\gamma w_{m, t}
$$

where $\gamma \in(0,1)$ is the constant replacement rate. Therefore unemployment benefit is fraction of minimum wage. The optimal allocations of household $i$ are given by:

$$
\begin{aligned}
c_{y, t}^{i} & =\frac{1}{1+\beta} x_{t}^{i} \\
c_{o, t+1}^{i} & =\frac{\beta}{1+\beta}\left(1+r_{t+1}\right) x_{t}^{i}
\end{aligned}
$$

\subsection{Firms}

This paper assumes ${ }^{3}$ the production function as follows:

$$
Y_{t}=A K_{t}^{\alpha}\left(G_{t} L_{t}\right)^{1-\alpha}
$$

where $K_{t}$ is the capital stock, $G_{t}$ is the public investment, $L_{t}$ is the labor input, $A$ is the constant parameter, and $\alpha \in(0,1)$ is the constant parameter. This paper assumes neither depreciation nor population growth. Public investment and unemployment benefit are financed by tax revenue from firms. The profit maximizetion conditions are given as:

\footnotetext{
${ }^{3}$ Barro [7] and Futagami and Morita and Shibata [8] assume public investment in the production function and public investment increases labor productivity.
}

$$
\begin{aligned}
& w_{m, t}=(1-\alpha) A K_{t}^{\alpha} G_{t}^{1-\alpha} L_{t}^{-\alpha} \\
& \left(1+\tau_{t}\right) r_{t}=\alpha K_{t}^{\alpha-1}\left(G_{t} L_{t}\right)^{1-\alpha}
\end{aligned}
$$

where $\tau_{t}$ is the contribution rate for firms to finance public investment and unemployment benefit. In the competitive equilibrium, $L_{t}=1$ and

$$
w_{c, t}^{*}=(1-\alpha) A K_{t}^{\alpha} G_{t}^{1-\alpha}
$$

hold. Using $w_{c, t}^{*}$ with Equation (5) and (9), $L_{t}$ is presented as:

$$
L_{t}=\mu^{-\frac{1}{\alpha}}
$$

Because $L_{t}$ is constant, the unemployment rate, $u_{t}=1-L_{t}$, is also constant for any period $t$.

\subsection{Government}

The government imposes tax on firms to finance public capital and unemployment benefit. Assuming a balanced budget, the budget constraint of the government is given by:

$$
\begin{aligned}
& E_{g, t}=\tau_{t} r_{t} K_{t} \\
& G_{t}=\lambda E_{g, t} \\
& u_{t} b_{t}=(1-\lambda) E_{g, t} \\
& \lambda \in(0,1)
\end{aligned}
$$

where $\tau_{t} r_{t} K_{t}$ is the tax revenue from firms, $E_{g, t}$ is the government expenditure, $G_{t}$ is the public investment, $u_{t} b_{t}$ is the total unemployment benefit, $\lambda$ is the constant ratio of public investment to tax revenue, and $(1-\lambda)$ is the constant ratio of unemployment benefit to tax revenue. Using Equation (5), (9), (10), (12), (14), and $u_{t}=1-L_{t}$ the budget constraint of the government is described as follows:

$$
\begin{aligned}
& \frac{u_{t} \gamma(1-\alpha)}{(1-\lambda)} A K_{t}^{\alpha} G_{t}^{1-\alpha}\left(1-u_{t}\right)^{-\alpha} \\
& =\frac{\tau_{t}}{1+\tau_{t}} \alpha A K_{t}^{\alpha} G_{t}^{1-\alpha}\left(1-u_{t}\right)^{1-\alpha}
\end{aligned}
$$

where

$$
\frac{u_{t} \gamma(1-\alpha)}{(1-\lambda)} A K_{t}^{\alpha} G_{t}^{1-\alpha}\left(1-u_{t}\right)^{-\alpha}
$$

is the total expenditure for unemployment benefit, and

$$
\frac{\tau_{t}}{1+\tau_{t}} \alpha A K_{t}^{\alpha} G_{t}^{1-\alpha}\left(1-u_{t}\right)^{1-\alpha}
$$

is the tax revenue. Hence $\tau_{t}$ is given by:

$$
\frac{\alpha \tau_{t}}{1+\tau_{t}}=\frac{\gamma(1-\alpha) u_{t}}{(1-\lambda)\left(1-u_{t}\right)}
$$


From Equation (9), (10), (12), (13), and (15), $G_{t}$ is given by:

$$
G_{t}=\left[\frac{\lambda A \gamma(1-\alpha)}{1-\lambda}\right]^{\frac{1}{\alpha}} u_{t}^{\frac{1}{\alpha}}\left(1-u_{t}\right)^{-1} K_{t}
$$

Tax rate $\tau_{t}$ is an endogenous variable delivered by a balanced budget and this ${ }^{4}$ assumption is the same as in Fanti and Gori [4]. Equation (15) shows that the tax rate is an ${ }^{5}$ increasing function of the unemployment rate and the ratio of public capital to tax revenue. The intuition is described as follows. If unemployment rate increases, then minimum wage increases and interest rate decreases because labor force becomes relatively scarce to capital. On the other hand, unemployment benefit $b_{t}$ also increases with an increase $w_{m, t}$ because unemployment benefit is fraction of minimum wage, and the total unemployment benefit $u_{t} b_{t}$ increases. We assume the ratio of total unemployment benefit to tax revenue is constant and balanced budget. From Equation (12) and (14), the relationship between total expenditure of unemployment benefit and tax revenue is denoted as $u_{t} b_{t}=(1-\lambda) \tau_{t} r_{t} K$. To satisfy balanced budget when total expenditure of unemployment benefit, $u_{t} b_{t}$, increases and interest rate, $r_{t}$, decreases with an increase in unemployment rate, $\tau_{t}$ should increase. Hence tax rate is an increasing function of unemployment rate.

From Equation (16), public investment is also an increasing function of unemployment rate; the reason for this is described as follows. When the unemployment rate increases, there are two effects to public investment. First, an increase in the unemployment rate increases $\tau_{t}$ from Equation (15), and this enlarges public investment because the tax revenue increases. Second, an increase in the unemployment rate decreases $r_{t}$ because labor force becomes relatively scarce to capital, and this decrease public investment because the tax revenue decreases. Comparing the two effects, the first effect dominates the second effect.

\section{Equilibrium}

In a basic overlapping generations model, the capital stock in period $t+1$ is equal to the savings in period $t$. The relationship between capital and savings is:

$$
K_{t+1}=\left(1-u_{t}\right) s_{t}^{e}+u_{t} s_{t}^{u}
$$

where $K_{t+1}$ is the capital in period $t+1,\left(1-u_{t}\right) s_{t}^{e}$ is the total savings of employees, and $u_{t} s_{t}^{u}$ is the total

${ }^{4}$ Fanti and Gori [6] also consider the exogenous replacement rates in extension.

${ }^{5}$ From equation (15), the derivative of tax rate with respect to unemployment rate gives:

$$
\frac{\mathrm{d} \tau_{t}}{\mathrm{~d} u_{t}}=\frac{\gamma(1-\alpha)\left(1+\tau_{t}\right)^{2}}{\alpha(1-\lambda)\left(1-u_{t}\right)^{2}}>0
$$

savings of unemployment. The dynamics of this economy is shown as follows:

$$
\begin{aligned}
& \frac{K_{t+1}}{K_{t}}=\frac{\beta Z}{1+\beta}\left[u_{t}^{\frac{1-\alpha}{\alpha}}+\gamma u_{t}^{\frac{1}{\alpha}}\left(1-u_{t}\right)^{-1}\right] \\
& Z \equiv((1-\alpha) A)^{\frac{1}{\alpha}}\left(\frac{\lambda \gamma}{1-\lambda}\right)^{\frac{1-\alpha}{\alpha}}
\end{aligned}
$$

where $K_{t+1} / K_{t}$ is the growth rate in the economy. To satisfy sustained growth, a large $A$ is assumed. From Equation (11), the unemployment rate, $u_{t}$, is constant and an increasing function of the constant mark-up rate $\mu$. The derivative of growth rate with respect to $\mu$ gives:

$$
\begin{aligned}
& \frac{\mathrm{d} g_{t}}{\mathrm{~d} \mu}=\frac{\mathrm{d} g_{t}}{\mathrm{~d} u_{t}} \frac{\mathrm{d} u_{t}}{\mathrm{~d} \mu}>0 \\
& g_{t} \equiv K_{t+1} / K_{t}
\end{aligned}
$$

Therefore the following proposition is established.

Proposition 1

An increase in the constant mark-up rate increases the minimum wage and promotes economic growth.

The total unemployment income $u_{t} b_{t}$ increases when $\mu$ increases. Therefore the savings of unemployment increases. On the other hand, an increase in $\mu$ has two effects on the total income of employees $\left(1-u_{t}\right) w_{m, t}$. First, an increase in $\mu$ directly decreases the total income of employees because unemployment increases. Second, an increase in $\mu$ increases $w_{m, t}$ because labor force becomes scarce and labor productivity is promoted. Comparing the two effects, the second effect dominates the first effect. Because the total income increases with an increase in $\mu$, the savings in this economy also increase. Therefore economic growth is promoted with an increase in $\mu$.

Finally, we focus on the effect of the ratio of public investment tax revenue on growth rate. Public investment increases with an increase in the constant ratio of public capital to tax revenue, from Equation (16). The derivative of growth rate with respect to $\lambda$ gives:

$$
\frac{\mathrm{d} g_{t}}{\mathrm{~d} \lambda}>0
$$

Therefore the following proposition is established.

Proposition 2

An increase in the ratio of public investment to tax revenue promotes economic growth.

An increase in the ratio of public investment to tax revenue, $\lambda$, promotes public investment, and this increases the minimum wage and unemployment benefit, from Equation (5). Therefore both the total wage income and total unemployment benefit increase with an increase in the ratio of public investment. This means that the 
total expenditure on unemployment benefit described as $u_{t} b_{t}=(1-\lambda) E_{g, t}$ increases even if the ratio of unemployment benefit to tax revenue decreases.

\section{Conclusion}

This paper presents a simple endogenous growth model with minimum wage and public investment that improves labor productivity. Minimum wage is an economic policy that helps reduce poverty and maintain a minimum standard of living. However, it is also claimed that minimum wage has a negative effect on employment and GDP. The relationship between minimum wage and economic growth is uncertain in earlier papers. This paper shows that a rise in minimum wage always promotes economic growth. Moreover, this paper shows that a rise in the ratio of public investment to tax revenue promotes economic growth.

\section{Acknowledgements}

The author would like to thank Tamotsu Nakamura, Takeshi Koba, and Masao Yamaguchi for their helpful comments and suggestions. The author is responsible for any remaining errors.

\section{REFERENCES}

[1] P. Cahuc and P. Michel, "Minimum Wage Unemployment and Growth,” European Economic Review, Vol. 40, No. 7, 1996, pp. 1463-1482. http://dx.doi.org/10.1016/0014-2921(95)00035-6

[2] M. Ravn and J. Sorensen, "Schooling, Training, Growth and Minimum Wages," Scandinavian Journal of Eco- nomics, Vol. 101, No. 3, 1999, pp. 441-457. http://dx.doi.org/10.1111/1467-9442.00165

[3] P. Askenazy, "Minimum Wage, Exports and Growth," European Economic Review, Vol. 47, No. 1, 2003, pp. 147-164. http://dx.doi.org/10.1016/S0014-2921(02)00187-3

[4] A. Irmen and B. Wigger, "National Minimum Wages, Capital Mobility and Global Economic Growth,” Economics Letters, Vol. 90, No. 2, 2006, pp. 285-289. http://dx.doi.org/10.1016/j.econlet.2005.08.011

[5] T. Tamai "Inequality, Unemployment, and Endogenous Growth in a Political Economy with a Minimum Wage," Journal of Economics, Vol. 97, No. 3, 2009, pp. 217-232. http://dx.doi.org/10.1007/s00712-009-0059-x

[6] L. Fanti and L. Gori, "On Economic Growth and Minimum Wages,” Journal of Economics, Vol. 103, No. 1, 2011, pp. 59-82. http://dx.doi.org/10.1007/s00712-011-0190-3

[7] R. J. Barro, "Government Spending in a Simple Model of Endogenous Growth,” Journal of Political Economy, Vol. 98, No. 1, 1990, pp. S103-S125. http://dx.doi.org/10.1086/261726

[8] K. Futagami, Y. Morita and A. Shibata, "Dynamic Analysis of an Endogenous Growth Model with Public Capital,” Scandinavian Journal of Economics, Vol. 95, No. 4, 1993, pp. 606-625. http://dx.doi.org/10.2307/3440914

[9] G. Glomm and B. Ravikumar, "Productive Government Expenditure and Long-Run Growth,” Journal of Economic Dynamics and Control, Vol. 21, No. 1, 1997, pp. 183-204. http://dx.doi.org/10.1016/0165-1889(95)00929-9

[10] A. Yakita, “Aging and Public Capital Accumulation," International Tax and Public Finance, Vol. 15, No. 5, 2008, pp. 582-598.

http://dx.doi.org/10.1007/s10797-007-9041-0 